\title{
ORIGINAL RESEARCH \\ Revisiting Job Satisfaction and Intention to Stay: A Cross-Sectional Study among Hospital Nurses in the Philippines
}

\author{
Lester C. Sapar ${ }^{1}$, Ryan Michael F. Oducado² \\ ${ }^{1}$ University of Negros Occidental-Recoletos, Philippines \\ ${ }^{2}$ College of Nursing, West Visayas State University, Philippines
}

Article Info
Article History:
Received: 8 February 2021
Revised: 3 April 2021
Accepted: 7 April 2021
Online: 27 August 2021
Keywords:
Intention; job satisfaction; nurses;
Philippines
Corresponding Author:
Ryan Michael Flores Oducado
College of Nursing, West Visayas
State University, Philippines
Email: rmoducado@wvsu.edu.ph
sectional study among hospital nurses in the Philippines. Nurse Media Journal of Nursing, 11(2), $133-143$. https://doi.org/10.14710/nmjn.v11i2.36557

\section{Introduction}

The effectiveness and efficiency of the healthcare delivery system are affected by the high turnover and shortage of nurses. The nursing workforce is an indispensable part of healthcare making up 59\% of the healthcare workforce (Haddad et al., 2020; World Health Organization [WHO], 2020a). However, the nursing profession continues to face shortages both globally and locally due to several factors including high turnover (Haddad et al., 2020). According to the WHO (2020a), there is a global shortfall of 5.9 million nurses, and those countries that suffer the most acute nurse shortages are low and lower-middle-income or developing countries.

Nursing turnover is a critical area of concern because nursing shortages lead to poor patient outcomes and higher rates of errors, morbidity, and mortality (Asegid et al., 2014; Haddad et al., 2020). The Philippines is a major exporter of nurses worldwide (Lorenzo et al., 2007; UbasSumagasyay \& Oducado, 2020). However, even the world's supplier of nurses like the Philippines also struggles with the nursing shortage problem. A study has shown those nurses' reports of low nurse and large patient ratio resulting in longer working hours suggests the existence of a nursing shortage in the country (Legaspi, 2019). Staffing and resource adequacy was also reported as the lowest aspect of the practice environment of Filipino nurses in another study conducted in Zamboanga, Philippines (Barandino \& Soriano, 2019). Unless greater investment is done to retain nurses in the Philippines, the anticipated shortage of nurses in the country is expected to be 
249,843 up to 290,000 by 2030 (WHO, 2020b; Philippine Overseas Employment Administration, 2020). The annual migration of at least 13,000 health workers contributes to this deficit (Philippine Overseas Employment Administration, 2020). The migration of nurses abroad leaves hospitals in the country the demands of efficient use of resources (Ubas-Sumagasyay \& Oducado, 2020) and greater investment and efforts should be made to retain nurses in the country.

Job satisfaction is a factor associated with the problems encountered in the recruitment and retention of nurses (Asegid et al., 2014). Nurses must operate in a safe and satisfying work environment for them to realize their potential in leading the way to improving health (Woolforde, 2019). However, nurses often work in problematic work environments that can deter nurses' full capacity to provide safe and quality nursing care (Barandino \& Soriano, 2019). Besides, when studying the work environment, attention should be given to two specific nurse outcomes: job satisfaction and intent to stay (Al-Hamdan et al., 2017). According to the Theory of Planned Behavior, attitude, in this study nurses' job satisfaction or their attitude towards their job, is considered a significant determinant of behavioral intention (Ajzen, 1991). The nursing shortage is seen as the consequence of having unmet these specific outcomes. Employers and administrators must be able to provide a satisfying workplace that is conducive to the growth and optimal functioning of nurses. After all, nurses are at the frontlines of the health system and excellence in nursing care produces excellent patient outcomes (Al-Hamdan, 2017); Kieft et al., 2014).

Meanwhile, while nurses' job satisfaction has received considerable attention among scholars, the results of studies are still mixed. A study on the work environment of nurses in the Philippines by Dones et al, (2016) has provided interesting yet conflicting insights on the current situation of nurses in the Philippines. The study disclosed that while physiologic and safety needs of the nurses are the areas that require great improvement, nurses are currently highly satisfied with their job and that they intend to remain in their present work environment (Dones et al., 2016). Another study among hospital staff nurses of Zambales, Philippines showed satisfactory results in terms of human relationships, job environment, workload, and benefits and promotions (Devera \& Maniago, 2017). Filipino nurses also rated their job satisfaction on a moderate to a high level in the study of Lapeña et al. (2017). However, there are also reports that nurses in the country are overworked and underpaid nurses (Crisostomo, 2020; Ubas-Sumagasyay \& Oducado, 2020). A study among the government hospital nurses of Samar, Philippines revealed nurses slightly unsatisfied with their job (Rosales et al., 2013). Despite some studies supporting the claim that nurses in the Philippines are satisfied with their job, migration and turnover rates of nurses are still high. Filipino nurses continuously migrating to other countries have endangered the Philippines quality of patient care services (Labrague et al., 2018a). Among the several reasons of nurses for leaving the country include poor compliance of nursing laws, high patient-nurses ratios, lack of professional growth and opportunities, poor benefits, and low income (CastroPalaganas et. al, 2017; Labrague et. al, 2018a; Labrague et. al, 2017; Lorenzo et al., 2007). A review study identified three main contributing factors of nurses' intent to stay: nurses' individual characteristics, professional characteristics, and organizational factors (Xue et al., 2020). At this backdrop, steps must be made in preventing high turnover rates of nurses and maintaining a committed nursing workforce (Labrague et. al., 2018b).

Job satisfaction is a recognized factor that influences the decision of nurses to stay in their current workplace (Al Hamdan et al., 2017; Caricati et al., 2014; Mrayyan, 2007). However, is this generalization applicable to Filipino nurses who were reportedly satisfied with their job but still sought opportunities elsewhere and especially abroad? It has also been suggested to look into and compare the job satisfaction and turnover intention of public and private hospitals (Legaspi, 2019). Consequently, the researchers felt the need to revisit and perform an empirical investigation of the current state of nurses' job satisfaction and intention to stay in their current work environment, address the contradicting findings of prior studies, and determine if job satisfaction can influence nurses' intention to stay. This study was conducted to assess nurses' job satisfaction and intention to stay in two selected hospitals in the Philippines. It also aimed to determine whether there are significant differences in nurses' intention to stay based on certain socio-demographic and work-related characteristics and if job satisfaction influences nurses' intention to stay in their current workplace. 


\section{Methods}

\subsection{Research design}

A cross-sectional survey design was employed in this investigation. The researchers collected the data needed for the study at one point in time to give a snapshot picture (Connelly, 2016) of the job satisfaction and intention to stay of Filipino hospital nurses.

\subsection{Setting and samples}

A total of 120 randomly selected registered nurses participated in this study. This study was conducted in two hospitals with $150-200$ bed capacity in the Western Visayas region of the Philippines. The two hospitals were selected since they were comparable in terms of the maximum number of patients that can be treated by the institution and the Nursing Directors showed interest in the study and granted approval to collect data in their institution. The sample size for this study was initially computed using Slovin's formula $\mathrm{n}=\mathrm{N} \div\left(1+\mathrm{Ne}^{2}\right)$. Inclusion criteria were a registered nurse in the Philippines, currently employed in the hospital, and granted consent to participate in the study. Volunteer nurses or trainees were excluded from the study. With a total population of 212 nurses from both hospitals, the desired sample size for the study was 139 . However, only the responses from the 6o nurses from each hospital were included in the study. Some questionnaires that were retrieved had no signed consent forms, others had no answers while the rest had incomplete data or were not fully accomplished. The researchers had the plan to return to the hospitals to gather additional data and complete the missing and lacking questionnaires or replace the samples but this was not done because of the nationwide lockdown as a response to the COVID-19 outbreak. Nonetheless, the 120 participants comprise $86.3 \%$ of the total needed sample or $56.6 \%$ of the total population of nurses included in the study.

\subsection{Measurement and data collection}

The Job Satisfaction Survey (JSS) and Intent to Stay Scale (ITSS) were used to gather data for this study. The instruments were administered in the English language. The JSS by Spector (1985) is a 36-item scale with nine subscales or facets measuring nurses' job satisfaction or attitude towards their job. The nine components of the JSS were nature of work, supervision, coworkers, communication, pay, promotion, contingent rewards (performance based rewards), fringe benefits, and operating procedures (required rules and procedures). A summated rating scale format was used and the participants responded from the six options per item ranging from "1-strongly disagree" to "6-strongly agree". Generally, higher scores indicate higher satisfaction. Translated into the summed scores, for the 4-item subscale, 4 to 12 scores are dissatisfied, 16 to 24 are satisfied, and between 12 and 16 are ambivalent. For the total satisfaction, 36 to 108 are dissatisfied, 144 to 216 are satisfied, and between 108 and 144 are ambivalent. The reported internal consistency reliability (coefficient alpha) of the total scale was 0.91 and test-retest reliability of 0.71. The Cronbach's alpha of the entire JSS for this study was 0.88 .

The ITSS by Price and Mueller (1986) was also utilized in this study to assess hospital nurses' intention to stay in their current workplace. The ITSS in this study consisted of four (4) items and was presented in a 5-point Likert scale with responses ranging from "1-strongly disagree" to "5strongly agree". To fit the ITSS for nurses, the term "institution or hospital" was used in the items presented. The ITSS was found to have a high Cronbach's alpha of o.89 (Markowitz, 2012). Higher scores indicated a higher level of intention to stay. To interpret the findings, the following scale of means was used in this study: 1.00 to 2.33 are intended to quit or low intention to stay, 2.34 to 3.66 are ambivalent or moderate intention to stay, and 3.67 to 5.00 are intended to stay or high intention to stay. A socio-demographic (age, sex, number of dependents, civil status, highest educational attainment) and work-related (monthly salary, type of hospital of present employment, nursing function, employment status, length of service, area of assignment) profile sheet was also utilized to collected nurses' characteristics.

The data for this study were gathered between January to February of 2020. Permission was asked first to responsible authorities (Hospital Administrator and Chief of Nursing Service Office) of each institution before the conduct of the study. Compliance with institutional requirements including ethics approval was taken into account and followed. Once approvals were granted, the researchers then proceeded with the recruitment process and personally distributed the selfadministered questionnaires to the participants enclosed in an envelope. Assistance was sought from the Nursing Service Office to ascertain the participants identified in the random selection of 
nurses using the lottery technique. Upon distribution of the questionnaires, informed consents were obtained and the participants were reminded that they could contact the researcher for any pertinent information concerning the study. Nurses were given the option to bring home the questionnaires as they requested to do but were informed to return the questionnaires after seven days from the time of the receipt of the research instrument. However, there were some instances when the participants requested an extension of the retrieval of the questionnaire. The contact details were indicated in the questionnaires for the participants to contact the researchers once the questionnaire had been accomplished and ready for retrieval. A maximum of one month was allotted for each institution for data gathering.

\subsection{Data analysis}

Data were analyzed using the IBM Statistical Package for the Social Sciences (SPSS) version 23. Categorical data were analyzed using frequency and percentage. Mean (M) and Standard Deviation (SD) were also used to describe the data. The median scores were also reported. Given that the sample was drawn randomly and the Kolmogorov-Smirnov test of normality suggested that the data do not deviate significantly from normal distribution, the t-test for independent samples and one-way ANOVA was used to test for differences while Pearson's $r$ was employed to test for correlation between variables.

\subsection{Ethical considerations}

This study was approved by the Unified Research Ethics Review Committee of the West Visayas State University (2019.GS-I_0o8). Written informed consent forms were signed by the participants.

\section{Results}

\subsection{Socio-demographic and work-related profile of nurses}

Table 1 shows the socio-demographic and work-related profile of the hospital nurses. The nurses had an average age of 30.52 years $(\mathrm{SD}=5.73)$, with $1.24(\mathrm{SD}=1.35)$ number of dependents, monthly income of 17,532 pesos or 350.64 USD ( 1 USD $=50$ PHP), and a length of service or had been working in their current hospital workplace for an average of 46 months. The majority were females (67.5\%), single (66.7\%), with Bachelor of Science in Nursing degree (95.8\%), staff nurse function (89.2\%), and regular or permanent employees (67.55). There were an equal number of nurses that responded in both public and private hospitals. $49.2 \%$ were from Specialty Units, $42.5 \%$ were wards and private rooms, and Nursing Service Office (8.3\%).

Table 1. Socio-demographic and work-related profile of nurses

\begin{tabular}{|c|c|c|c|c|c|}
\hline Profile & $\mathrm{M}$ & SD & Median & $\mathrm{f}$ & $\%$ \\
\hline Age (years) & 30.52 & 5.73 & 30 & & \\
\hline Younger (30 years old and below) & & & & 68 & 56.7 \\
\hline Older (31 years old above) & & & & 52 & 43.3 \\
\hline \multicolumn{6}{|l|}{ Sex } \\
\hline Female & & & & 81 & 67.5 \\
\hline Male & & & & 39 & 32.5 \\
\hline Number of Dependents & 1.24 & 1.35 & 1 & & \\
\hline None & & & & 52 & 43.2 \\
\hline $1-2$ & & & & 47 & 49.2 \\
\hline 3 or more & & & & 21 & 17.5 \\
\hline \multicolumn{6}{|l|}{ Civil Status } \\
\hline Single & & & & 80 & 66.7 \\
\hline Married & & & & 40 & 33.3 \\
\hline \multicolumn{6}{|l|}{ Highest Educational Attainment } \\
\hline Bachelor degree & & & & 115 & 95.8 \\
\hline Master degree & & & & 5 & 4.2 \\
\hline Monthly Salary (Pesos) & 17,532 & 7280.0 & 18,000 & & \\
\hline Lower (PHP 17,531 and below) & & & & 58 & 48.3 \\
\hline Higher (PHP 17,532 and above) & & & & 62 & 51.7 \\
\hline
\end{tabular}


Table 1. Continued

\begin{tabular}{|c|c|c|c|c|c|}
\hline Profile & $\mathrm{M}$ & SD & Median & $\mathrm{f}$ & $\%$ \\
\hline \multicolumn{6}{|l|}{ Type of Hospital } \\
\hline Private & & & & 60 & 50.0 \\
\hline Public & & & & 60 & 50.0 \\
\hline \multicolumn{6}{|l|}{ Nursing Function } \\
\hline Staff & & & & 107 & 89.2 \\
\hline Administrative/Supervisory & & & & 13 & 10.8 \\
\hline \multicolumn{6}{|l|}{ Employment Status } \\
\hline Contractual & & & & 39 & 32.5 \\
\hline Regular/Permanent & & & & 81 & 67.5 \\
\hline Length of service (months) & 46 & 35.22 & 36 & & \\
\hline Less than 24 months & & & & 38 & 31.7 \\
\hline 24 to 48 months & & & & 35 & 29.2 \\
\hline 48 to 72 months & & & & 30 & 25.0 \\
\hline More than 72 months & & & & 17 & 14.2 \\
\hline \multicolumn{6}{|c|}{ Area of assignment or Unit category } \\
\hline Nursing Service Office & & & & 10 & 8.3 \\
\hline Ward/Private Rooms & & & & 51 & 42.5 \\
\hline Specialty Units & & & & 59 & 49.2 \\
\hline
\end{tabular}

\subsection{The Proportion of level of job satisfaction and intention to stay}

Table 2 reveals that more than half (58.3\%) of the nurses were ambivalent or neither satisfied nor dissatisfied with their job. Moreover, Table 2 illustrates that a big majority (80.8\%) of the nurses were ambivalent or neither had the intent to stay nor to quit their current workplace, and only very few (9.2\%) had high intention to stay in their current institution.

Table 2. Proportion of level of job satisfaction and intention to stay

\begin{tabular}{lcc}
\hline Levels of job satisfaction and intention to stay & f & $\%$ \\
\hline Job satisfaction & & \\
Satisfied & 42 & 35 \\
Ambivalent & 70 & 58.3 \\
Dissatisfied & 8 & 6.7 \\
Intention to stay & 11 & 9.2 \\
Intend to stay & 97 & 80.8 \\
Ambivalent & 12 & 10 \\
Intend to quit & & \\
\hline
\end{tabular}

\subsection{Components of job satisfaction of nurses}

The overall general satisfaction score of nurses was $138.29(\mathrm{SD}=18.34)$. The satisfaction of hospital nurses on the nine components of the JSS can also be gleaned in Table 3. Nurses were satisfied with the nature of work $(M=18.95, \mathrm{SD}=2.50)$, supervision $(\mathrm{M}=17.78, \mathrm{SD}=3.66)$, and coworkers $(\mathrm{M}=17.78, \mathrm{SD}=2.88)$ which were ranked first to third respectively. On the other hand, nurses were dissatisfied in terms of the fringe benefits $(\mathrm{M}=12.69, \mathrm{SD}=4.11)$ and operating conditions $(\mathrm{M}=12.18, \mathrm{SD}=2.58)$.

\subsection{Nurses' intention to stay and influencing factors}

Table 4 shows that the general intention to stay of nurses had a mean score of $2.97(\mathrm{SD}=0.58)$. It is also shown in Table 4 that there was a significant difference in the intent to stay of hospital nurses when grouped according to monthly salary $(\mathrm{t}=2.078, \mathrm{p}=0.040)$. Nurses with a higher salary of PHP 17,532 and above $(\mathrm{M}=3.08, \mathrm{SD}=0.63)$ intend to stay than those with lower salaries $(\mathrm{M}=2.86, \mathrm{SD}=0.51)$. There was also a significant difference in the intent to stay of hospital nurses when grouped according to the type of hospital $(\mathrm{t}=2.472, p=0.015)$. Nurses from the public hospital $(\mathrm{M}=3.10, \mathrm{SD}=0.62)$ had a higher intention to stay than those from the private hospital $(\mathrm{M}=2.84, \mathrm{SD}=0.52)$. Table 5 also shows that there was a significant positive $(\mathrm{r}=0.285, p=0.002)$ correlation between nurses' job satisfaction and nurses' intention to stay. 
Table 3. Components of nurses' job satisfaction

\begin{tabular}{lcccc}
\hline \multicolumn{1}{c}{ Satisfaction } & M & SD & Interpretation & Rank \\
\hline Nature of work & 18.95 & 2.50 & Satisfied & 1 \\
Supervision & 17.78 & 3.66 & Satisfied & 2 \\
Co-workers & 17.78 & 2.88 & Satisfied & 3 \\
Communication & 15.54 & 3.63 & Ambivalent & 4 \\
Pay & 15.06 & 2.98 & Ambivalent & 5 \\
Promotion & 14.37 & 2.85 & Ambivalent & 6 \\
Contingent rewards & 13.94 & 3.54 & Ambivalent & 7 \\
Fringe benefits & 12.69 & 4.11 & Dissatisfied & 8 \\
Operating conditions & 12.18 & 2.58 & Dissatisfied & 9 \\
Total satisfaction & 138.29 & 18.34 & Ambivalent & \\
\hline
\end{tabular}

Table 4. Differences and correlation of independent variables to nurses' intent to stay

\begin{tabular}{|c|c|c|c|c|}
\hline Variables & $\mathrm{M}$ & SD & T statistics & $p$-value \\
\hline Intention to stay & 2.97 & 0.58 & & \\
\hline $\operatorname{Age}^{\dagger}$ & & & 0.073 & 0.942 \\
\hline Younger & 2.97 & 0.57 & & \\
\hline Older & 2.97 & 0.61 & & \\
\hline $\operatorname{Sex}^{\dagger}$ & & & 0.711 & 0.478 \\
\hline Female & 2.94 & 0.50 & & \\
\hline Male & 3.03 & 0.73 & & \\
\hline Number of Dependents ${ }^{\ddagger}$ & & & 1.831 & 0.165 \\
\hline None & 3.09 & 0.46 & & \\
\hline $1-2$ & 2.89 & 0.64 & & \\
\hline 3 or more & 2.87 & 0.71 & & \\
\hline Civil Status $^{\dagger}$ & & & 0.440 & 0.661 \\
\hline Single & 2.99 & 0.50 & & \\
\hline Married & 2.94 & 0.72 & & \\
\hline Highest Educational Attainment ${ }^{\dagger}$ & & & 1.893 & 0.061 \\
\hline Bachelor degree & 2.95 & 0.57 & & \\
\hline Master degree & 3.45 & 0.76 & & \\
\hline Monthly Salary ${ }^{\dagger}$ & & & $2.078 *$ & 0.040 \\
\hline Lower & 2.86 & 0.51 & & \\
\hline Higher & 3.08 & 0.63 & & \\
\hline Type of Hospital $^{\dagger}$ & & & $2.472^{*}$ & 0.015 \\
\hline Private & 2.84 & 0.52 & & \\
\hline Public & 3.10 & 0.62 & & \\
\hline Nursing Function ${ }^{\dagger}$ & & & 1.454 & 0.149 \\
\hline Staff & 2.94 & 0.56 & & \\
\hline Administrative/Supervisory & 3.19 & 0.72 & & \\
\hline Employment Status $^{\dagger}$ & & & 1.901 & 0.060 \\
\hline Contractual & 3.12 & 0.52 & & \\
\hline Regular & 2.90 & 0.61 & & \\
\hline Length of Service ${ }^{\ddagger}$ & & & 1.213 & 0.308 \\
\hline Less than 24 months & 2.87 & 0.50 & & \\
\hline 24 to 48 months & 2.99 & 0.51 & & \\
\hline 48 to 72 months & 2.96 & 0.77 & & \\
\hline More than 72 months & 3.19 & 0.50 & & \\
\hline Area of Assignment ${ }^{\ddagger}$ & & & 2.155 & 0.120 \\
\hline Nursing Service Office & 3.25 & 0.58 & & \\
\hline Ward/Private Rooms & 3.02 & 0.47 & & \\
\hline Specialty Units & 2.88 & 0.66 & & \\
\hline Satisfaction ${ }^{\S}$ & & & $0.285^{*}$ & 0.002 \\
\hline Satisfied & 3.11 & 0.58 & & \\
\hline Ambivalent & 2.97 & 0.48 & & \\
\hline Dissatisfied & 2.28 & 0.94 & & \\
\hline
\end{tabular}

${ }^{t}$-test, ${ }^{*}$ ANOVA, \&Pearson's $r,{ }^{*} p<0.05$ 


\section{Discussion}

This study assessed hospital nurses' job satisfaction and intention to stay in their current workplace. This study found that more than half of the nurses were neither satisfied nor dissatisfied were their job. This finding is similar to the results among Jordanian nurses (Mrayyan, 2007) and Polish and Swedish nurses (Serafin et al., 2019). Nigerian nurses in public hospitals were also moderately satisfied with their work (Samson-Akpan et al., 2015). An average level of general job satisfaction was also found by Legaspi (2019) among Filipino nurses employed both locally and overseas. Our finding is however in contrast to the study of Dones et al. (2016), Devera and Maniago (2017), and Lapeña et al. (2017) among Filipino nurses and of Mohite et al. (2014) among Indian nurses where nurses were generally satisfied with their job and work environment. The variation in the results of studies may be due to the different measures used by the researchers to assess nurses' job satisfaction at the same time the variable like job satisfaction can change over time therefore results can be limited or potentially biased due to the crosssectional design of studies conducted examining nurses' job satisfaction.

When studying nurses' job satisfaction, it is vital to critically examine the different domains or facets of the job to have a better understanding of their attitude towards their work. It is noteworthy that among the nine domains of job satisfaction, nurses in this study reported the highest satisfaction in terms of the nature of the job. Prior studies using the JSS similarly noted the nature of the work was the highest scored subscale of the JSS among Filipino nurses (Rosales et al., 2013) and Saudi nurses (Baker \& Alshehri, 2020). Legaspi (2019) also found that "the chance for the nurses to do things for other people" or social service was motivating and satisfying for nurses. The satisfaction of Filipino nurses appears to come mainly from the work itself of being a nurse or the job task themselves. This may explain that despite the not ideal working conditions and not competitive pay for nurses in the country, Filipino nurses still find nursing a fulfilling and satisfying profession. On the other hand, nurses reported the lowest satisfaction in terms of the fringe benefits (monetary and non-monetary) and operating conditions or operating policies and procedures at work. Nurses were also dissatisfied with the fringe benefits and received the lowest mean score on this domain in the studies of Rosales et al. (2013) and Baker and Alshehri (2020).

It was also demonstrated in this study that a big majority of nurses were ambivalent about whether they will stay or not in their current workplace. It was also notable that only a few nurses intend to stay in their current job. A study conducted in Jordan found the nurses were also neutral in reporting their intention to stay at their current workplace (Mrayyan, 2005, 2007). Filipino nurses of a study conducted in the province of Samar were also undecided whether or not to leave their organization (Labrague et. al, 2018a). The result of this study is however in contrast to the findings of (Dones et al., 2016) that reported majority of Filipino nurses intend to remain in their present work environment. A significant proportion of the sample in the study of Dones et al. (2016) involved nurses from the academe while our sample included nurses working in the hospital setting. Also, the different research instruments used to assess the intention to stay in the present job could have influenced the results of the studies. For instance, the study of Dones et al. (2016) assessed intention to remain in their present job within the next six months while our study assessed nurses' intention to stay in their work for a longer period (e.g., retirement).

In this study, we also found that nurses in the public hospital and those nurses with higher salaries had higher intentions to stay. On the contrary, Jordanian nurses in the private hospital had a higher intention to retain their jobs compared to nurses in the public hospital (Mrayyan, 2005). It was also earlier found that nurses' intention to stay rates varied between those working in non-teaching and teaching hospitals (Mrayyan, 2007). Nonetheless, the result of this study is not an unexpected finding given that the salaries of Filipino nurses in the private hospitals are typically lower and not at par with the salaries of nurses working in the public hospitals. We tried to check and compare the monthly salary of nurses between the two hospitals in this study. The average monthly salary of nurses in the private hospital was only PHP 11,700.00 or 234 USD while the average monthly salary of nurses in the public hospital was PHP 23,400.00 or 468 USD and this was statistically significant $(t=-14.711 p=0.000)$. While salary is one of the factors why Filipino nurses aboard like their job, locally-employed nurses are dissatisfied with their salary (Legaspi, 2019). Similarly, compensation and benefits received the lowest positive response and low salary or monetary compensation was a common reason for intending to leave their job in a survey conducted by Dones et al., (2016) among Filipino nurses. A study related that salary was an essential predictor driving Nigerian nurses (Akinwale \& George, 2020) and Jordanian nurses' 
(Al Momani, 2017) job satisfaction. While this finding in our study is not surprising anymore, our research provides empirical and up-to-date evidence regarding the disparity of salary between public and private hospitals in the country. To keep nurses in their position, the institution could intervene through satisfactory wages (McHugh \& Ma, 2014). This study suggests that efforts should be made to gradually raise the salary of nurses, especially in the private sector to address the growing needs of nurses.

Finally, it was revealed in this study that nurses' job satisfaction was significantly related to their intention to stay in their job. Job satisfaction significantly contributes to nurses' intention to stay. The result is consistent with findings reported from studies conducted among nurses in Canada (Sourdif, 2004), China (Li et al., 2020; Wang et al., 2012), and South Ethiopia (Asegid et al. 2014). A review study also disclosed that job satisfaction was positively associated with the intention to stay in the organization (Al Zamel et al., 2020). Among Filipino nurses, it was likewise found that job satisfaction strongly predicted turnover intention (Labrague et al., 2018b). Moreover, the result of this study supports the Theory of Planned Behavior which states that attitude is considered a significant determinant of behavioral intention (Ajzen, 1991; Atencion et al., 2019; Ditching et al., 2020). In this study, nurses' attitude towards their job or job satisfaction is positively linked with their intention to stay in their current workplace. It may be necessary for policy-makers and hospital administrators to work on improving nurses' satisfaction to retain qualified and experienced nurses and put a stop to the brain drain of skilled professionals in the country.

\section{Implications and limitations}

Our result has important implications for policymakers and nursing administrators given the felt shortage of nurses in the country and across the globe. Efforts should be made to tip scale to the favorable side of job satisfaction. Increasing the job satisfaction of nurses can be a step aimed at improving the quality of services rendered to the patients. When nurses are satisfied with their job, they are better able to render quality nursing care. Also, steps must be made to prevent the high turnover rates of nurses and retain organizationally committed and experienced nurses. Policies and regulations of hospitals as well as the benefits of the nurses should be improved. These facets of the job of nurses along with those where nurses were ambivalent about such as contingent rewards, promotion, and pay should be given more attention.

This study bears certain limitations and these are as follows. This study is limited among nurses in two middle-level hospitals in the Philippines and our study failed to reach the desired sample given the constraints of the pandemic. Caution is warranted when generalizing and using the findings of this study. Additionally, the cross-sectional research design of our study cannot infer cause and effect among the study variables likewise it cannot track temporal changes hence results can be limited or potentially biased. There may be changes in the nurses' work satisfaction and turnover intentions during the current pandemic. Also, the use of self-administered questionnaires lends itself to self-reported bias and the possibility of social desirability. Despite the limitations, our study contributed to a better understanding of nurses' job satisfaction and intention to stay in the local setting.

\section{Conclusion}

Nurses are generally neither satisfied nor dissatisfied with their job however, it is vital to look into the different domains or aspects of the work when studying job satisfaction to better understand the sources of nurses' satisfaction, contentment, and fulfillment at work. Additionally, few nurses plan to stay in their current workplace. This study also affirms that the satisfaction of nurses about their job is positively linked with their intention to stay in their organization. The more the nurses are satisfied, the higher is their intention to stay. It is highlighted in this study that steps should be made in developing strategies to improve nurses' job satisfaction and to encourage nurses to remain in their current workplace. Paying attention to issues pertaining to nurses' job satisfaction, addressing nurses' needs, and increasing their salary along with the other facets of job satisfaction are focal points of action to ensure the adequate supply of nurses. The result of this study also calls for more attention to be given to increasing the salary of nurses particularly in the private sector to help halt the loss of skilled professionals in the country. 


\section{Acknowledgment}

Mr. Sapar would like to thank the Commission on Higher Education of the Philippines for the scholarship granted to him that was instrumental in the completion of this study.

\section{Author contribution}

All authors participated sufficiently in the concept, design, analysis, writing, or revision of the manuscript.

\section{Conflict of interest}

The authors declare no conflicts of interest.

\section{References}

Ajzen, I. (1991). The theory of planned behavior. Organizational Behavior and Human Decision Processes, 5O(2), 179-211. http://dx.doi.org/10.1016/0749-5978(91)90020-T

Akinwale, O. E., \& George, O. J. (2020). Work environment and job satisfaction among nurses in government tertiary hospitals in Nigeria. Rajagiri Management Journal, 14(1), 71-92. https://www.emerald.com/insight/publication/issn/o972-9968

Al Momani, M. (2017). Factors influencing public hospital nurses' intentions to leave their current employment in Jordan. International Journal of Community Medicine and Public Health, 4(6), 1847-1853. http://dx.doi.org/10.18203/2394-6040.ijcmph20172143

Al Zamel, L. G., Lim Abdullah, K., Chan, C. M., \& Piaw, C. Y. (2020). Factors influencing nurses' intention to leave and intention to stay: An integrative review. Home Health Care Management \& Practice, 32(4), 218-228. https://doi.org/10.1177/1084822320931363

Al-Hamdan, Z., Manojlovich, M., \&Tanima, B. (2017). Jordanian nursing work environments, intent to stay, and job satisfaction. Journal of Nursing Scholarship, 49(1), 103-110. https://doi.org/10.1111/jnu.12265

Asegid, A., Belachew, T., \& Yimam, E. (2014). Factors influencing job satisfaction and anticipated turnover among nurses in Sidama zone public health facilities, South Ethiopia. Nursing Research and Practice, Article ID 909768. https://doi.org/10.1155/2014/909768

Atencion, B. C. S., Alingalan, A. F., Oducado, R. M. F., Cordova, J. D. N., Dumaguing, M. C. M., \& Suaboksan, M. T. T. (2019). Factors associated with intention to report child abuse among district hospital nurses in Iloilo, Philippines. International Journal of $\begin{array}{lll}\text { Caring } \quad \text { Sciences, } & \text { 210-217. }\end{array}$ http://www.internationaljournalofcaringsciences.org/docs/22_oducado_12_1.pdf

Baker, O., \& Alshehri, B. (2020). The relationship between job stress and job satisfaction among Saudi nurses: A cross-sectional study. Nurse Media Journal of Nursing, 1O(3), 292-305. https://doi.org/10.14710/nmjn.v10i3.32767

Barandino, J. P., \& Soriano, G. P. (2019). Practice environment and work-related quality of life among nurses in a selected hospital in Zamboanga, Philippines: A correlational study. Nursing Practice Today, 6(4), 223-228. https://doi.org/10.18502/npt.v6i4.1944

Caricati, L., Sala, R. L., Marletta, G., Pelosi, G., Ampollini, M., Fabbri, A., Ricchi, A., Scardino, M., Artioli, G., \& Mancini, T. (2014). Work climate, work values and professional commitment as predictors of job satisfaction in nurses. Journal of Nursing Management, 22(8), 984-994. https://doi.org/10.1111/jonm.12079

Castro-Palaganas, E., Spitzer, D. L., Kabamalan, M. M. M., Sanchez, M. C., Caricativo, R., Runnels, V., Labonté, R., Murphy, G. T., \& Bourgeault, I. L. (2017). An examination of the causes, consequences, and policy responses to the migration of highly trained health personnel from the Philippines: The high cost of living/leaving - a mixed method study. Human Resources for Health, 15(1), 1-14. https://doi.org/10.1186/s12960-017-0198-z

Connelly, L. M. (2016). Cross-sectional survey research. Medsurg Nursing, 25(5), 369-370. http://www.medsurgnursing.net/archives/16sep/369.pdf

Crisostomo, S. (2020). 'Overworked, underpaid' nurses want better conditions. The Philippine Star. https://www.philstar.com/headlines/2020/07/18/2028768/overworked-underpaidnurses-want-better-conditions 
Devera, R., \& Maniago, J. (2017). Nurses' perceptions on professional practice environment and job satisfaction in select hospitals of Zambales, Philippines. International Journal of Current Research, 9 (12), 62503-62511. https://www.journalcra.com/article/nurses\%E2\%80\%99perceptions-professional-practice-environment-and-job-satisfaction-select-hospitals

Ditching, N. A., Furatero, A. G. F., Iquiña, R. V. S., Sabulao, A. D. M., Supremo, J. M., \& Oducado, R. M. F. (2020). Factors associated with nursing students' intention to report needlestick injuries: Applying the theory of planned behavior. Nurse Media Journal of Nursing, 1O(3), 234-243. https://doi.org/10.14710/nmjn.v10i3.31975

Dones, L., Paguio, J., Bonita, S., Balabagno, A., \&Pagsibigan, J. (2016). Working environment of nurses in the Philippines: A preliminary study. Philippine Journal of Nursing, 86(2), 4-10. http://www.pna-pjn.com/research/oo1/

Haddad, L. M., Annamaraju, P., \& Toney-Butler, T. J. (2020). Nursing shortage. StatPearls. https://www.ncbi.nlm.nih.gov/books/NBK493175/

Kieft, R. A., de Brouwer, B. B., Francke, A. L., \& Delnoij, D. M. (2014). How nurses and their work environment affect patient experiences of the quality of care: A qualitative study. BMC Health Services Research, 14(1), 1-10. https://doi.org/10.1186/1472-6963-14-249

Labrague, L. J., Gloe, D., McEnroe, D. M., Konstantinos, K., \& Colet, P. (2018b). Factors influencing turnover intention among registered nurses in Samar Philippines. Applied Nursing Research, 39, 200-206. https://doi.org/10.1016/j.apnr.2017.11.027

Labrague, L. J., McEnroe-Petitte, D. M., Gloe, D., Tsaras, K., Arteche, D. L., \& Maldia, F. (2017). Organizational politics, nurses' stress, burnout levels, turnover intention and job satisfaction. International Nursing Review, 64(1), 109-116. https://doi.org/10.1111/inr.12347

Labrague, L. J., McEnroe-Petitte, D. M., Tsaras, K., Cruz, J. P., Colet, P. C., \& Gloe, D. S. (2018a). Organizational commitment and turnover intention among rural nurses in the Philippines: Implications for nursing management. International Journal of Nursing Sciences, 5(4), 403408. https://doi.org/10.1016/j.ijnss.2018.09.001

Lapeña, L. F. R., Tuppal, C. P., Loo, B. G. K., \& Abe, K. H. C. (2017). Transformational and transactional leadership styles of nurse managers and job satisfaction among Filipino nurses: A pilot study. Nurse Media Journal of Nursing, $7(2), \quad 65-78$. https://doi.org/10.14710/nmjn.v7i2.15171

Legaspi, R. S. E. (2019). A comparison of job satisfaction among Filipino nurses employed in the Philippines and overseas. Philippine Journal of Health Research and Development, 23(1), 38-47. http://scinet.dost.gov.ph/union/Downloads/261-593-1-SM_367710.pdf

Li, X., Zhang, Y., Yan, D., Wen, F., \& Zhang, Y. (2020). Nurses' intention to stay: The impact of perceived organizational support, job control and job satisfaction. Journal of Advanced Nursing, 76(5), 1141-1150. https://doi.org/10.1111/jan.14305

Lorenzo, F. M. E., Galvez-Tan, J., Icamina, K., \& Javier, L. (2007). Nurse migration from a source country perspective: Philippine country case study. Health Services Research, 42(3), 14061418. https://doi.org/10.1111/j.1475-6773.2007.00716.x

Markowitz, G. A. (2012). Faculty intent to stay and the perceived relationship with supervisor at a career-focused university (Doctoral Dissertation). University of Miami. https://scholarship.miami.edu/discovery/fulldisplay/alma991031447585202976/o1UOML INST:ResearchReposi

McHugh, M. D., \& Ma, C. (2014). Wage, work environment, and staffing: Effects on nurse outcomes. Policy, Politics, \& Nursing Practice, 15(3-4), $72-80$. https://doi.org/10.1177/1527154414546868

Mohite, N., Shinde, M., \& Gulavani, A. (2014). Job satisfaction among nurses working at selected tertiary care hospitals. International Journal of Science and Research, 3(6), 1006-1012. https://www.ijsr.net/get_abstract.php?paper_id=2014410

Mrayyan, M. T. (2005). Nurse job satisfaction and retention: comparing public to private hospitals in Jordan. Journal of Nursing Management, 13(1), 40-50. https://doi.org/10.1111/j.1365-2834.2004.00453.x

Mrayyan, M. T. (2007). Jordanian nurses' job satisfaction and intent to stay: Comparing teaching and non-teaching hospitals. Journal of Professional Nursing, 23(3), 125-136. https://doi.org/10.1016/j.profnurs.2006.12.006

Philippine Overseas Employment Administration (2020). Governing board resolution No. o9. https://www.poea.gov.ph/gbr/2020/GBR-09-2020.pdf 
Price, J., \& Mueller, C. (1986). Handbook of organizational measurement. Pitman.

Rosales, R., Rosales G. \& Labrague, L. (2013). Nurses job satisfaction and burnout: Is there a Connection? International Journal of Advanced Nursing Studies, 2(1), 1-10 https://doi.org/10.14419/ijans.v2i1.583

Samson-Akpan, P. E., Edet, O. B., Ojong, I. N., \& Asuquo, E. F. (2015). Job satisfaction among nurses in public hospitals in Calabar, Cross River State Nigeria. American Journal of Nursing Science, 4(4), 231-237. https://doi.org/10.11648/j.ajns.20150404.22

Serafin, L., Bjerså, K., \& Doboszynska, A. (2019). Nurse job satisfaction at a surgical ward-a comparative study between Sweden and Poland. Medycyna Pracy, 7o(2), 155-167. https://doi.org/10.13075/mp.5893.00768

Sourdif, J. (2004). Predictors of nurses' intent to stay at work in a university health center. Nursing \& Health Sciences, 6(1), 59-68. https://doi.org/10.1111/j.1442-2018.2003.00174.x

Spector, P. E. (1985). Measurement of human service staff satisfaction: Development of the job satisfaction survey. American Journal of Community Psychology, 13, 693-713.

Ubas-Sumagasyay, N. A., \& Oducado, R. M. F. (2020). Perceived competence and transition experience of new graduate Filipino nurses. Jurnal Keperawatan Indonesia, 23(1), 48-63. https://doi.org/10.7454/jki.v23i1.1071

Wang, L., Tao, H., Ellenbecker, C. H., \& Liu, X. (2012). Job satisfaction, occupational commitment and intent to stay among Chinese nurses: A cross-sectional questionnaire survey. Journal of Advanced Nursing, 68(3), 539-549. https://doi.org/10.1111/j.1365-2648.2011.05755.x

Woolforde, L. (2019). Beyond Clinical Skills: Advancing the healthy work environment. Journal for Nurses in Professional Development, 35(1), 48-49. https://doi.org/10.1097/NND.0000000000000510

World Health Organization. (2020a). State of the world's nursing 2020: Investing in education, jobs and leadership. https://apps.who.int/iris/handle/10665/331677

World Health Organization. (2020b). Urgent need for investment in nursing. https://www.who.int/philippines/news/detail/o7-04-2020-urgent-need-for-investmentin-nursing

Xue, T., Jiang, W. B., Ma, M. D., Zhang, J., Lu, M. H., \& Jiang, Y. M. (2020). Factors associated with the nurses' intent to stay in China, Japan, and Korea: An integrative review. Frontiers of Nursing , 7(3), 269-278. https://doi.org/10.2478/fon-2020-0037

Copyright (C) 2021 NMJN. This article is an open access article distributed under the terms and conditions of the Creative Commons Attribution-Share Alike 4.0 (CC BY-SA) International License (https://creativecommons.org/licenses/by-sa/4.o). 